5,13

LA -5142

\title{
Oxidation Behavior of Transit Capsule T-47
}

THIS DOCUMENT CONFIRMED AS UNCLASSIFIED 
This report was prepared as an account of work sponsored by the Unitod States Government. Neither the United States nor the United States Atomic Energy Commission, nor any of their emplovees, nor any of their contrec. tors, subcontractors, or their employees, makes any warranty, express or im. plied, or assumes any legai liability or responsibility for the accuracy. com. pleteness or usefulness of any information, apparatus, product or procese dis. closed, or represents that its use would not infringe privately owned rights.

Printed in the United Sutes of America. Availeble from Nationel Technical Information Service

U. S. Depertmant of Commerce

S2w Port Roval Roud

Springtield, Virginiv 22151

Price: Printed Copy 53.00: Wieroliche 50.85 


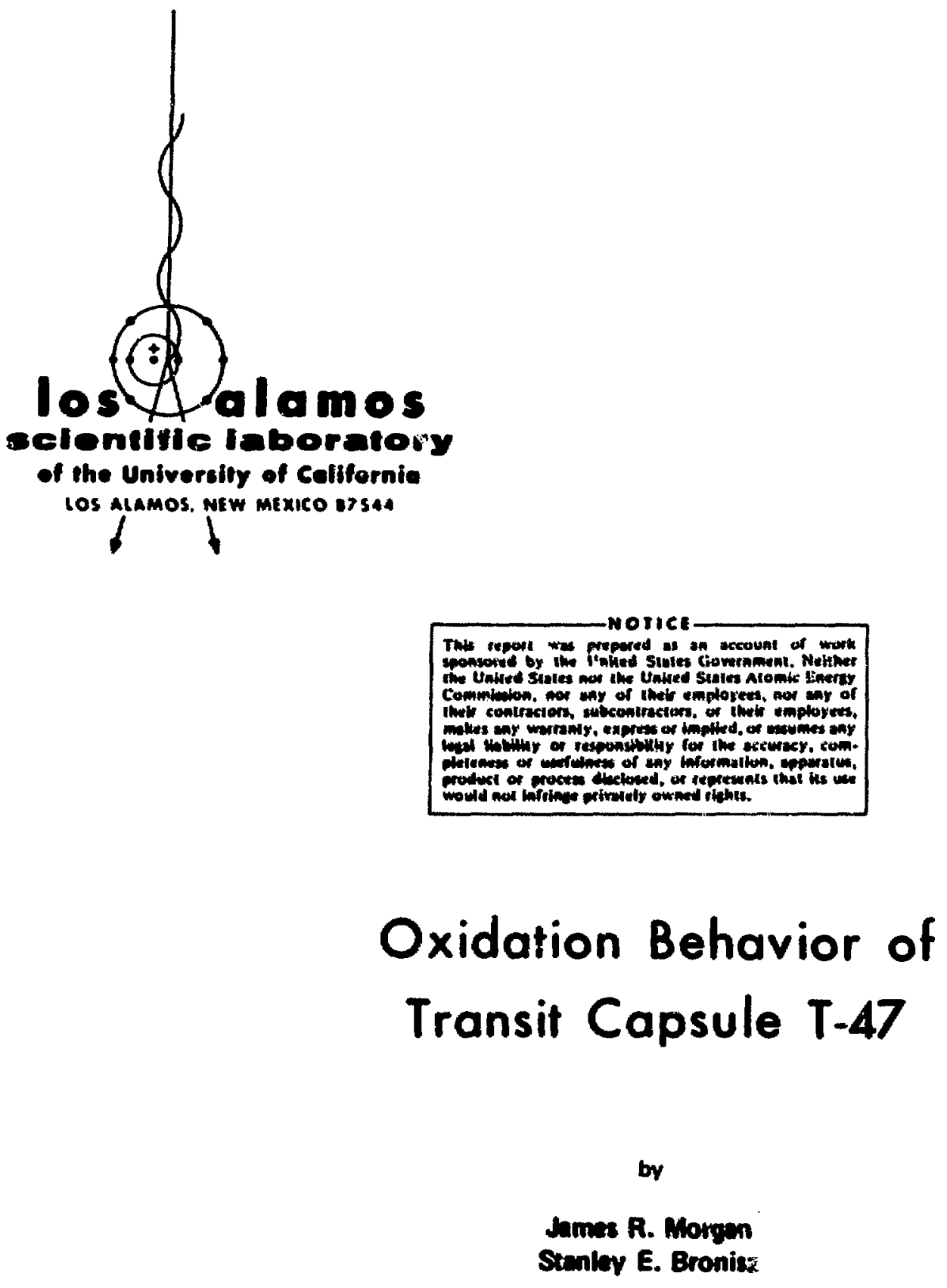




\title{
OXIDATION BEHAVIOR OF TRANSIT CAPSULTE T-47
}

\author{
by
}

James R. Morgan and Stanley E. Bronisz

\begin{abstract}
Tranait Capsule T-47, which had been dropped onto a concret: pad at terminal velocity, was heated by an internal electric heater to simulate the heat generntion in a Iight captule during exposure to a natural environment. Catastrophic oxidation of the cantalum-alloy strength member and liner occurred, exposing fuel simulant after 4.5 days. The progres of capsule deterioration was monitored by timelapec cinematography.
\end{abstract}

\section{INTRODUCTION}

Following a launch-pad accident or a normal reentry from orbit, a heat-source capsule from a Transit or Pioneer radioisotopic thermoelectric generator (RTG) will remain on the ground for an unspecified period before it is recovered. It is imperative, therefore, to know how long the capsule in that condition will continue to contain its fuel.

Furmace tests run by TRW' had indicated that the fuel would become exposed to the atmosphere within a few days, or weeks at most. The tantalum-alloy strength member and liner oxidized, as did the molybdenum component of the $\mathrm{ThO}_{2}$ /Mo cermet (SSCS) fuel simulant used in the capsules. The volume expansion accompanying the formation of oxidation products, which are less dense than the metals from which they are formed, caused the platinum-rhodium outer shells of the capsules to deform and fail, thus exposing the fuel simulant.

The AEC/SNS Transit Safety Officer, Neal Goldenbers, asked the Los Alamos Scientific Labontory (LASL) to test an internally heated Transit capsule containing SSCS in a natural environment and to observe the course of its oxidation. The test was to determine whether changes in wind speed and direction, surrounding temperature, and min would produce a different oxidation pattern from that observed in the furnace tests. It was also requested that a visual record of the oxidation be obtained for use in the Transit safety review procedures.

\section{EXPERIMENTAI, DETAILS}

The sample used in this experiment was Capsule T-47, a Transit safery-evaluation test capsule containing SSCS, which had been subjected to simulated reentry heating and a terminal-velocity drop onto conerete to simulate the return from orbit of a heatsource capaule from a Transit RTG. The capsule's condition after these tests is shown in Fig. 1 at the end of this report. The impact had distorted the capsule and had formed a longitudinal crack about $0.4 \mathrm{in}$. long and 0.02 to 0.03 in. vride in the outer platinum-rhodium alloy cladding. Apperently, the tancabum-alloy strenth member (T-111) and liner (Ta-10W) were unbreached by the impact." The remaining emistive coating shows up as the darkest areas in the figure. Normally, this platinized alumina conting covers nearly all the cladding, but the impact had caused it to spall.

The thermal power of a Transit heat source is $850 \mathrm{~W}$. In the test, the fuel heat generation was simulated by an clectrical heater inserted into the capsule. Figure 2 is a diagram of the capsule and heater. A diamond-tiyped molybdenum core drill was driven along the principal Iengitudinal axis of the capeule to a depth of 4.65 in. to allow the 4in. long electric heater to be centered in the final asembly. The core drill was made of molyodenum so that it could be left in the capeule without

-Orher tex caponles whih similar cladding dannes were found to be otherwive wobreached. See Ref. 1. 
unnecessarily introducing a new type of material into the system, and its size (0.600 in. o.d. and 0.546 i.d.) was such that the amount of molybdenum in the drill shank just equaled the amount lost by removal of the cermet core, so the drilling did not change the total amount of molybdenum in the capsule.

The integrity of the outer oxygen barrier was preserved by gold-welding a platinum thimble inside the molybdenum core drill, as shown in Fig. 3, after the capsule had been baked overnight in a vacuum furnace at about $175^{\circ} \mathrm{C}$ to remove all the chlorothene cutting fluid used in drilling.

The "star" pressure-relief indentation near the end of the capsule was filled in with gold by welding, after which a 0.010-in.-diam vent hole was drilled through the platinum-rhodium jacket about 0.2 in. from the weld. (The curcent design uses a drilled hole instead of the star indentation to relieve the helium pressure caused by radioactive decay of the fuel.)

Time-lapse cinematography was used to document the progress of oxidation. Figure 4 is a general view of the experimental setup. Four front-silvered mirrors were arranged as shown in Fig. 5, so that the image on each frame of film exposed by the fixed main camera contained a plan view, an elevation view, and an end view of the capsule, as well as a view of the 24-h clock and day counter. Zero hour on the clock was 9:00 a.m. local time.

One frame of the 16-mm color film was exposed every $2 \mathrm{~min}$. Thus one $24 \mathrm{~h}$ day was "condensed" into $45 \mathrm{sec}$ of screen time when projected at silent speed of 16 frames/sec, or into $30 \mathrm{sec}$ of screen time when projected at sound speed of 24 frames/sec."

A second, movable camera was meant to record closeup details of the oxidation, but almost all of its film footage was rendered useless by mechanical and other difficulties.

The three electric lamps shown in Fig. 4 were set about $4 \mathrm{ft}$ from the capsule and gave a light intensity only about $1 / 2$ to 1 f-stop lower than normal sunlight. This was a good level of illumination because it allowed day and night and the passage of clouds to be distinguished but avoided serious overexposure or underexposure. To minimize the possibility of the photo lamps' burning out during the night when the experiment was unattended, they were dimmed by a switching cirucit that cut the power by, one half except during a 2 -sec pulse each time that the camera shutter operated.

Four platinum-rhodium thermocuples were spot welded to the outer jacket of the capsule, two were positioned 1 and 3 in. deep in the soil beneath the capsule, and a seventh was spor wclded to the edge of the heater sheath.

-The motion-picture film from this tes is not part of this publicarion.
The thermocouple locations are shown in Fig. 6. The signals from the thermocouples were fed to a multipoint recorder.

The power required by the heater was supplied as an ac voltage controlled by an adjustable transformer (Powerstat) and measured by multiplying voltmeter and ammeter readings.

Recording meteorological instruments located about 100 yards from the capsule were used to monitor the wind direction and velocity, temperature, precipitation, humidity, and barometric pressure.

\section{EXPERIMENTAL RESULTS}

Figure 7 shows the specimen on location at the test site before the test. The test plan called for increasing the power to $\sim 827 \mathrm{~W}$ and holding it at that level until the capsule failed. (The reference design power at the time of the experiment was $827 \mathrm{~W}$. This was later increased to $850 \mathrm{~W}$.) TRW had calculated the capsule surface temperature to be $\sim 620^{\circ} \mathrm{C}$ at this power level. ${ }^{1}$

Power was applied to the heater at 10:00 a.m. May $11 \mathrm{th}, 1971$, held at a low level for $0.5 \mathrm{~h}$, and then increased comparatively rapidly, as shown in Fig. 8. However, the planned power level was not reached because the heater failed at $808 \mathrm{~W}$. Before the failure, ac current evidently leaked from the heater to the thermocouples and caused the temperature recorder to show spuriously low values. The recorder worked properly as soon as the heater burned out completely and opened the heater circuit.

The capsule did not reach thermal equilibrium during this initial heating, but it was evident that the predicted equilibrium temperature extrapolated from Fig. 8 would be considerably higher than that calculated by TRW. Inquiry revealed that the TRW calculations were made for a capsule with an intact platinized-alumina emissivity coating. The fact that most of the black coating was missing from the capsule used in the experiment probably accounts for the observed temperatures' being significantly higher than the calculated values.

Careful inspection of the capsule after this first heating revealed no change in its appearance. The strength member, as seen through the crack in the cladding, still had a metallic luster.

The burned-out heater was replaced, and the test was resumed. This time, the power was increased much more slowly, and thermal equilibrium was nearly reached at each step. Figure 9 is a temperature-vs-power plot derived during this slow heating. The temperatures are nominal averages, because wind-velocity variations caused sizable fluctuations in the capsule surface temperature, especially at higher power levels. Power was held constant at $430 \mathrm{~W}$ 
when it was observed that this level gave a surface temperature of about $620^{\circ} \mathrm{C}$.

The progress of the oxidation and its effects on the capsule are shown in Figs. 10 through 14. The first evidence of oxidation of the tantalum-alloy strength member was the development of a gold-colored temper oxide on this member beneath the crack in the cladding. This was observed approximately $2-1 / 2 \mathrm{~h}$ after the capsule reached $620^{\circ} \mathrm{C}$. The crack was noticeably enlarged after 8 or $10 \mathrm{~h}$ at $620^{\circ} \mathrm{C}$, and it grew progressively as the cladding was forced away from the strength member by the formation of oxide. The rate of tantalum oxidation as indicated by the cladding deformation appeared to increase as the rupture in the platinum-rhodium cladding grew.

After 4 days, the crack had extended longitudinally to the junction of the cylindrical and hemispherical sections of the capsule and had branched to form two roughly circumferential cracks that tended to separate the hemispherical end sections from the cylindrical body. The circumferential crack at the end of the capsule where the cap had been welded to the jacket followed a path adjacent to the weld on the hemispherical cap.

The capsule ruptured near the 0.010-in.-diam vent hole after 60 or $70 \mathrm{~h}$ at $620^{\circ} \mathrm{C}$, but this crack was not associated with the weld used to close the star. The main rupture system that had loosened the hemispherical ends of the cladding may have relieved some of the stresses in these areas.

As the tantalum oxide formed, it tended to remain a coherent mass and appeared to be extruded through the cracks in the platinum-rhodium cladding. The oxide particles were adherent enough to resist the wind forces quite well, but, after enough oxide had been formed, its own weight caused it to break.

The first visible fallout of tantalum oxide from the main rupture occurred after about 3.3 days at temperature. After about 4.5 days, a lump of tantalum oxide powder about $3 / 8$ in. in diam fell from the capsule. This was taken to be the first effective uncovering of the thoria-molybdenum wafers. Visual inspection at about this time revealed the exrensive network of acicular white crystals of $\mathrm{MOO}_{3}$ shown in Fig. 15. It seems probable that the $\mathrm{MoO}_{3}$ in this location was derived from the molybdenum in the fuel. After $114 \mathrm{~h}$ at $620^{\circ} \mathrm{C}$, the second heater burned out and the test was terminated.

Figure 16 is a summary of the measurements made during the oxidation test. The wind velocity varied considerably, from about 3 to $40 \mathrm{mph}$, during the test, and the temperature at each of the seven thermocouple locations reflected the changes in velocity. The response was not immediate because of the capsule's heat capacity and the insulating effect of the ground, and equilibrium was not attained. However, the data plotted in Fig. 16 suggest that each mile per hour increase in wind velocity cools a
Transit capsule by about $3^{\circ} \mathrm{C}$. Only a trace of precipitation occurred during the test, so no information about the effect of rain on the oxidation process was obtained.

The general trend of temperature with time shown in Fig. 16 is worth some comment. The thermocouples so located that they were not directly affected by the formation of oxide (TC's 1, 5, 6, and 7) showed a general overall increase in temperature, whereas those that were pushed outward and insulated by the formation of the oxide tended to reflect a decrease in temperature. This suggests that the overall effect of the oxidation is to add an insulating layer to the capsule, which increases the temperature at the oxidation interface beneath the layer and also, assuming the easy availability of oxygen, increases the oxidation rate.

After the heater had failed, the capsule was left undisturbed for a whole day, to allow observation of the effect of wind on the powdery oxide and also to allow time for project personnel to view the test before it was moved to the LASL Group CMB-5 laboratory for disassembly and detailed analysis.

Reasonably careful handling during transportation to the laboratory kept most of the oxide in the capsule, but, when the capsule was inverted during the examination, the oxide fell out. Figure 17 shows the capsule after the oxide hid fallen out. The edges of the SSCS disks are clearly visible. The exposed region of the SSCS was bounded by the remains of the strength member and liner, which had embrittled.

Figure 18 shows a fracture on the impact side of the capsule. It seems plausible that here the force of the impact created a minute crack that escaped notice before oxidation enlarged it. If that is so, the crack's minute size and sheltered location at the bottom of the capsule could have impeded the ingress of oxygen enough to account for the relatively slow oxidation observed during the time that the capsule was at elevated temperature.

\section{CAPSULE DISASSEMBLY}

The capsule end containing the vent hole is shown in Fig. 19. The 0.01-in.-diam vent hole is barely visible as a black dot just left of the weld that covered the original star. The rupture caused by oxide formation began at the vent hole and later propagated through the edge of the weld. The close proximity of the much larger main fracture (the large field of white in the photograph) probably relieved the stresses in the cladding material and also provided an escape route for some of the oxide formed near the vent. So the rupturing near the vent was probably less drastic in this test than it would have been had the vent been the only breach in the cladding. 
The other end of the capsule is shown in Fig. 20. The needles in the white material are $\mathrm{MoO}_{3}$, most of which came from the molybderum core drill tube, although some may have come from the fuel.

The capsule with the cladding removed is shown in Fig. 21. The extent of the area in which the tantalum was totally oxidized is easily seen. However, those strengthmember surfaces that were in close contact with the cladding throughout the test (the impact surface, and the region diametrically opposite the hole) were only tarnished.

Further disassembly showed that the inner surface of the strength member and both surfaces of the liner were tarnished. The entire liner was brittle. The strength member retained some ductility where it was only tarnished, although the surfaces of those areas had been embrittled to a depth of 0.01 in.

The fuel simulant from the capsule is shown in Fig. 22. The white material at the top of the photograph delineates the extent of severe oxidation in the area exposed by the failure of the tantalum-alloy members adjacent to the rupture. The end of the core drill with the diamondimpregnated hard-facing alloy still intact is visible at the left. The shank of the core drill is still bright where it was burnished in the drilling operation. Close inspection shows also that the tartalum shims are stril present between the simulant disks. Oxidation of the sinims and of the molybdenum in the simulant was quite limited during the test.

The experiment had to be terminated earlier than planned because it was impossible to replace the second burned-out electric heater without catastrophically disturbing the capsule components. Therefore, the ultimate fate of the fuel simulant was not determined. Nonetheless, the test demonstrated conclusively that the fuetcontainment lifetime of a Transit or Pioneer capsule on the ground is quite limited.

The 430-W test power input is, respectively, one-half and two-thirds of the nominal Transit and Pioneer thermal powers. Even at this reduced power level, the capsule fajled, exposing fuel in about 4.5 days. At higher power levels, the failure would have occurred even sooner, because of enhanced oxidation at the higher temperatures. At the low power used in the experiment, the capsule responded initially as if its emissive coating were intact.
Once the oxide had formed on the strength member and had produced an insulating layer, however, the experiment ceased to be realistic and, instead, indicated only the progress, not the velocity, of the deterioration. The temperature distribution in a Transit capsule has not been calculated as a function of the progress of the oxidation, but the test results suggest that the oxide's insulating effect raises the internal temperatures which, in turn, increase the oxidation rate.

The particular damage sustained by the cladding before exposure of a capsule to the atmosphere will control the initial stage of oxidation. In the present case, the crack in the cladding was the controlling factor. If the capsule had not been damaged, the controlling factor would have been the 0.01-in.-diam helium vent hole drilled through the cladding. About 3 days passed before a rupture started at this hole, suggesting that after 3 days in air an undamaged capsule would be at the approximate starting condition of this test capsule. Because about 4.5 days were required to expose the fuel simulant in this test, it appears that the lifetime of an undamaged Transit capusle with an intact emissive coating is about a week. Damage involving a breach in the coating or cladding would decrease this time, whereas reducing the size of the vent hole (in the absence of other damage) would increase it.

\section{ACKNOWLEDGMENTS}

So many people within LASL contributed to this experiment that it would be extremely difficult to give proper credit to each. We would be remiss, however, not to mention the special assistance of W. F. Clark and D. C. Murphy of Group SD-6, who drilled the impacted capsule and installed the platinum thimble so skillfully, and of $\mathbf{R}$. G. Sturgess and W. D. Stoms of Group CMB-7, who designed and built the triggering system to coordinate the photo lamps and camera shutters.

\section{REFERENCE}

1. TRW Systems Group, "Transit RTG Final Safety Analysis Report, Vol. III," Report No. TRW(A)-11464-0493, page G-113, (March 1, 1971). 


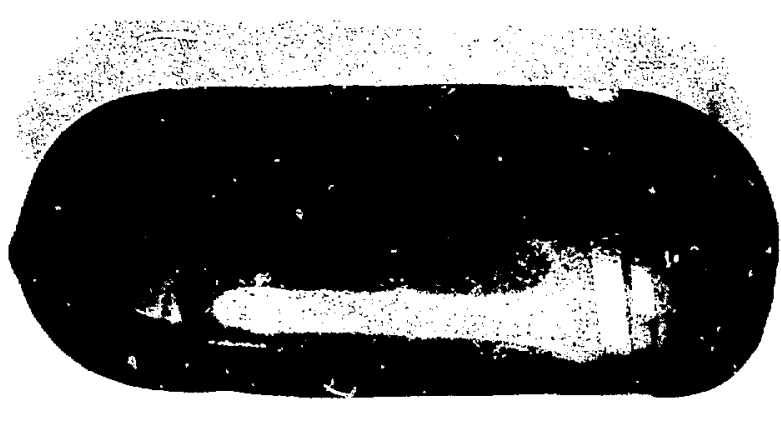

Fig. 1.

Capsule T-47, after impact on concrete, but before installation of the beater and tbermocouples.

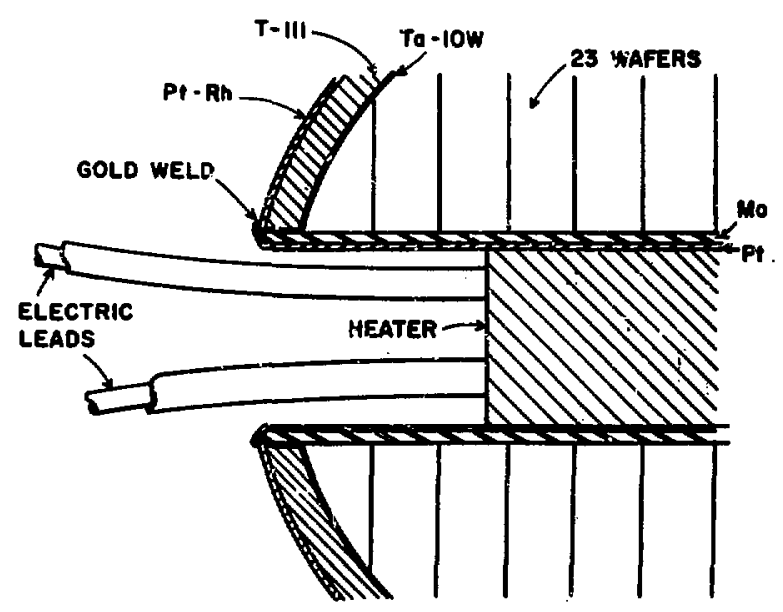

Fig. 3.

Platinum-tbimble closure detail.

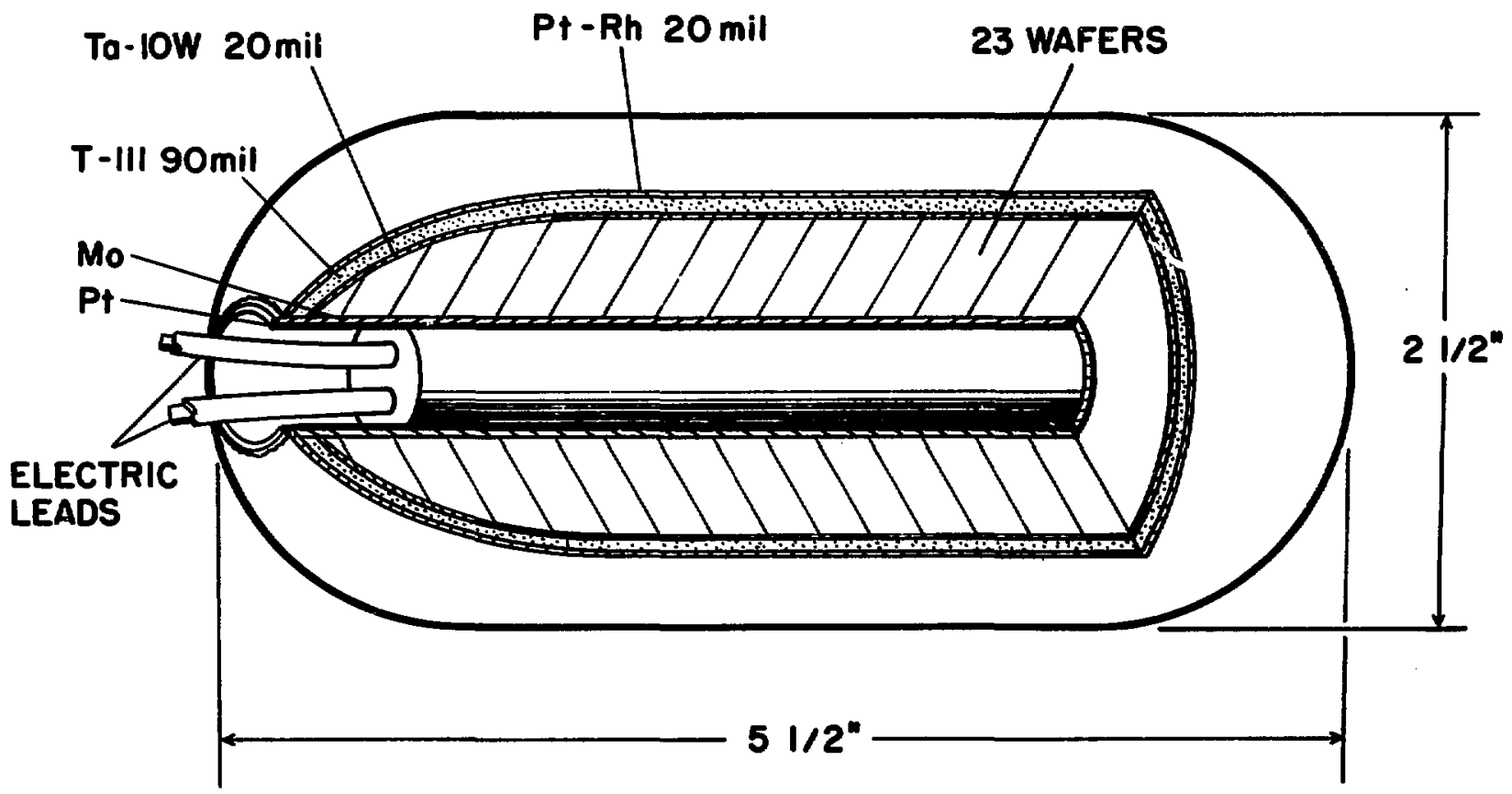

Fig. 2.

Heater inistallation detail. 


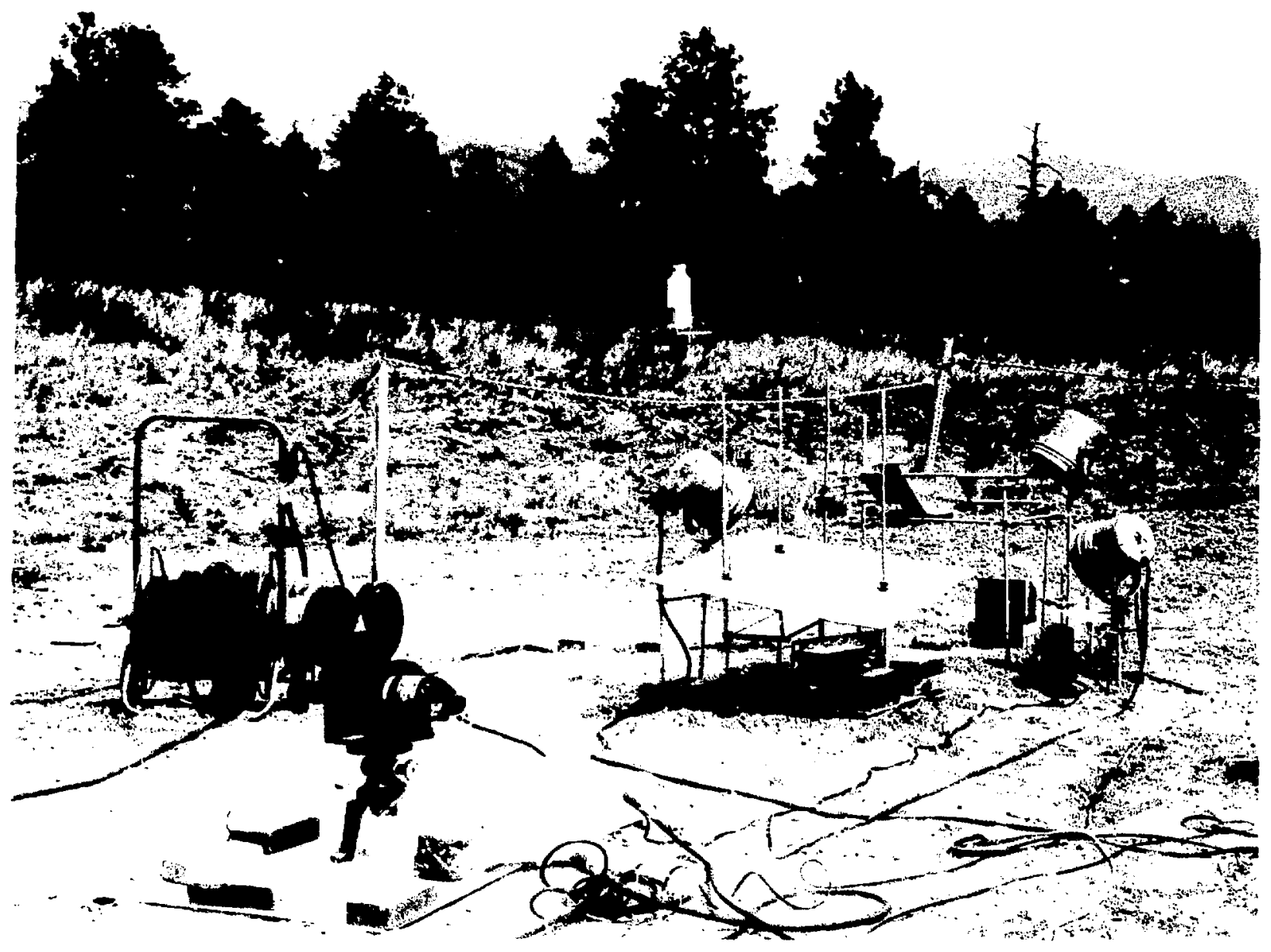

Fis. 4.

Tbe capsule-oxidation experimental installation.

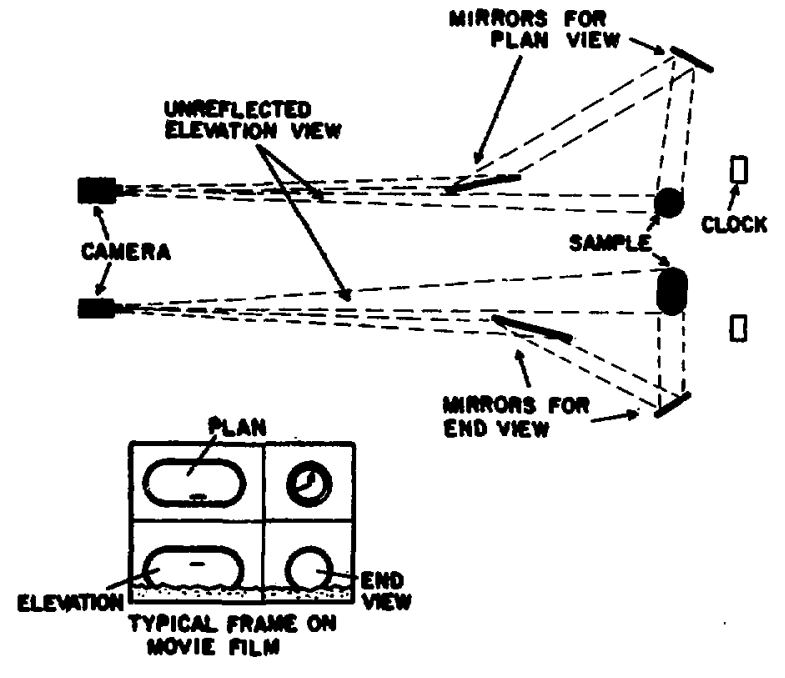

Pig. 5.

Mirror placement to provide tbree views of tbe capsule and a time record on eacb frame of film.

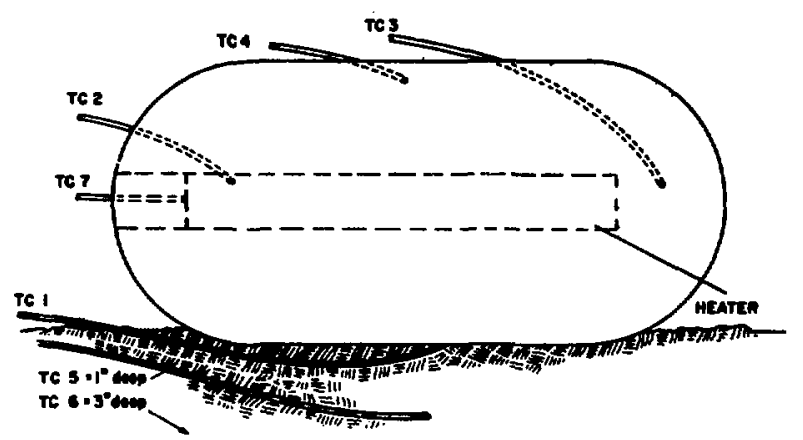

Fig. 6.

Tbermocouple placement. 


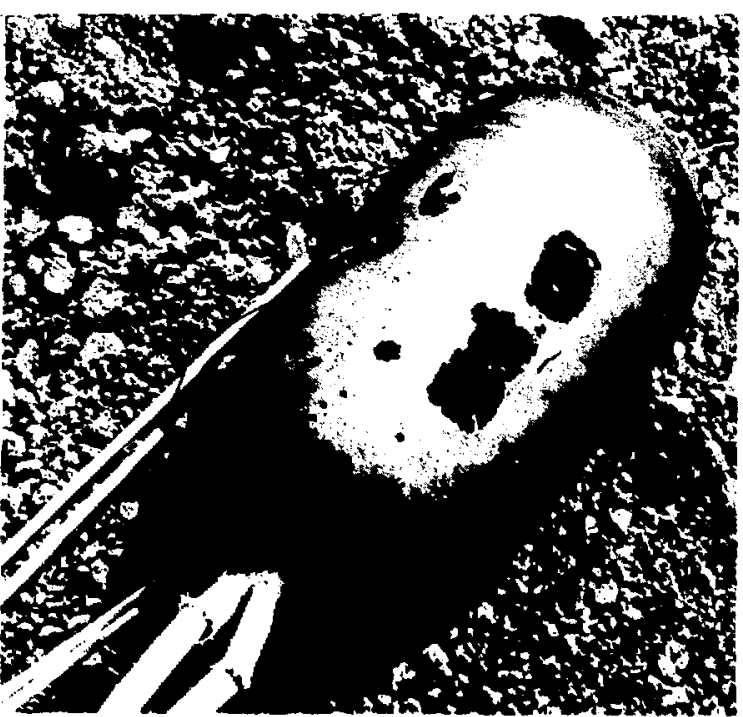

Fis. 7.

Capsule $T-47$ in position before tbe test.

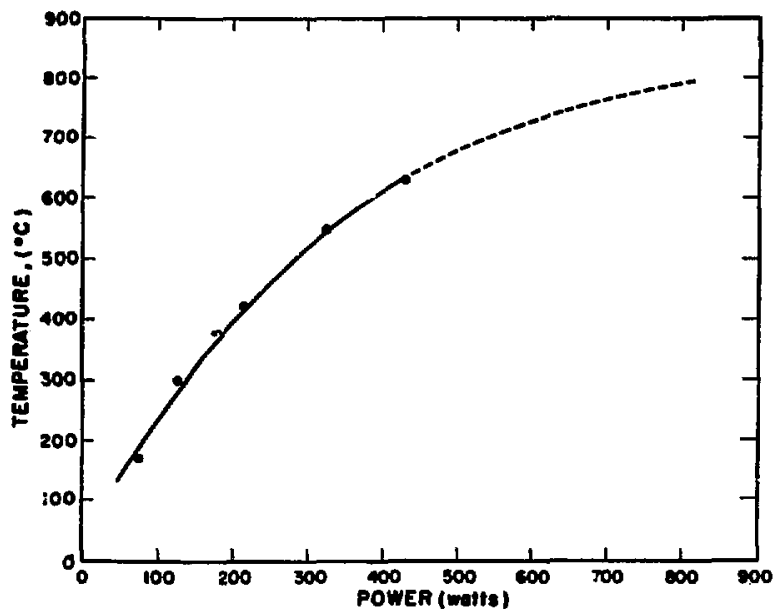

Fig. 9.

Power-os-surface temperature of the second beater.

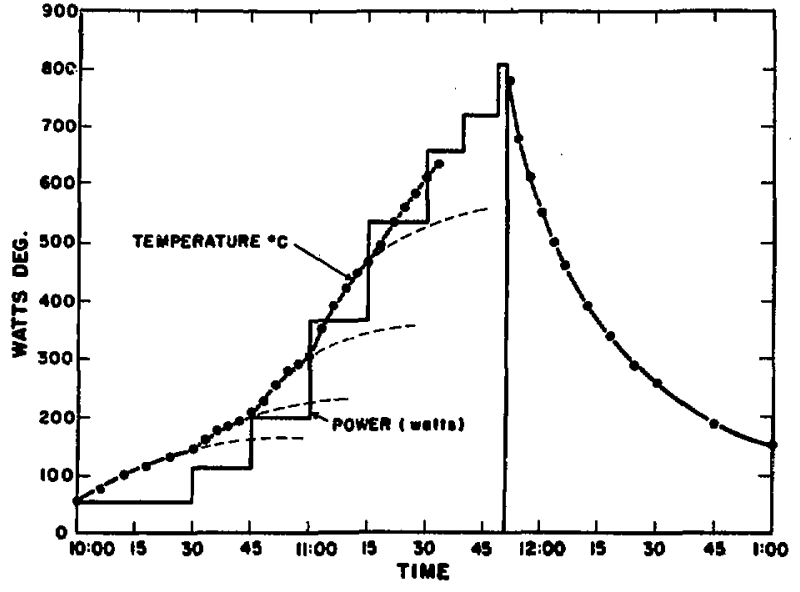

Fig. 8.

Temperature bistory of the capsule during the life of the first beater.

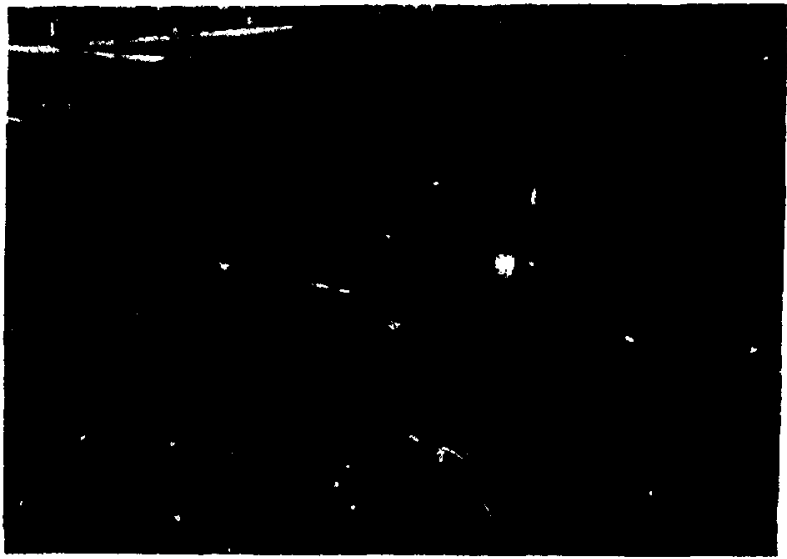

Fig. 10.

Capsule after $\sim 22$ b at 430-W test power. Saturday, May 15, 1971, 9:00 a.m. 


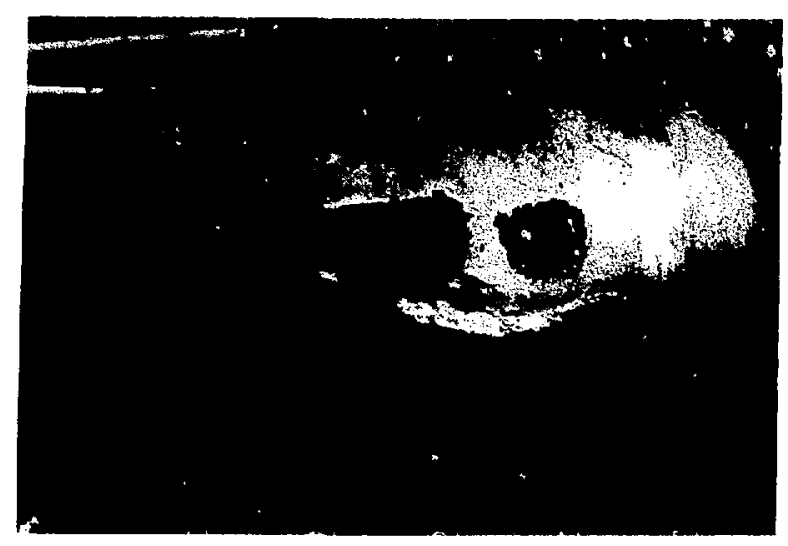

Fir. 11 .

Capsule after $47 \mathrm{~b}$, Sunday May 16, 1971, 10:00 a.m.

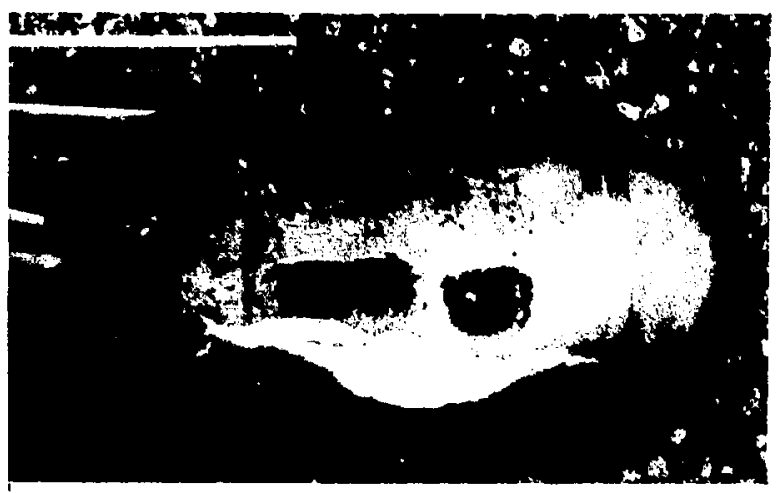

Fig. 12.

Capsule after $70 \mathrm{~b}$, Monday, May 17, 1971, 9:00 a.m.

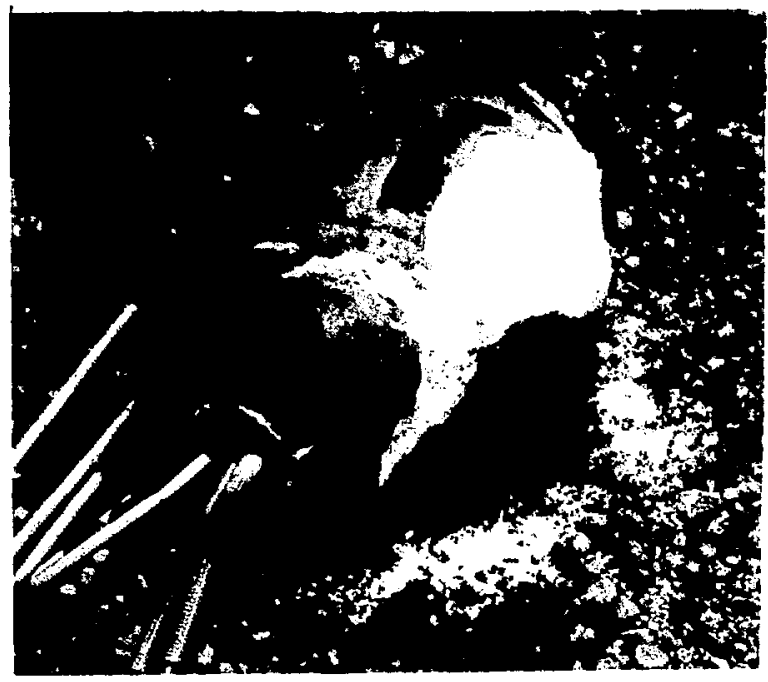

Fig. 13.

Capsule after 99 b, Tuesday, May 18, 1971, 2:00 p.m.

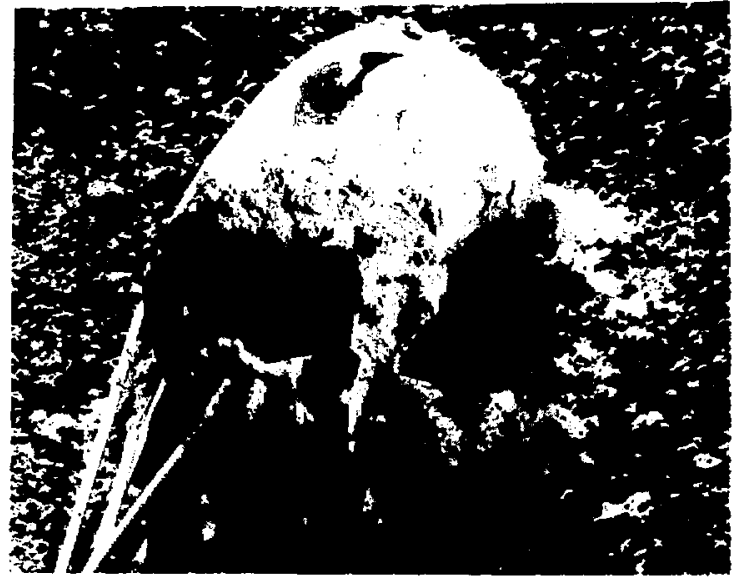

Fig. 14.

Capsule after failure of second beater.

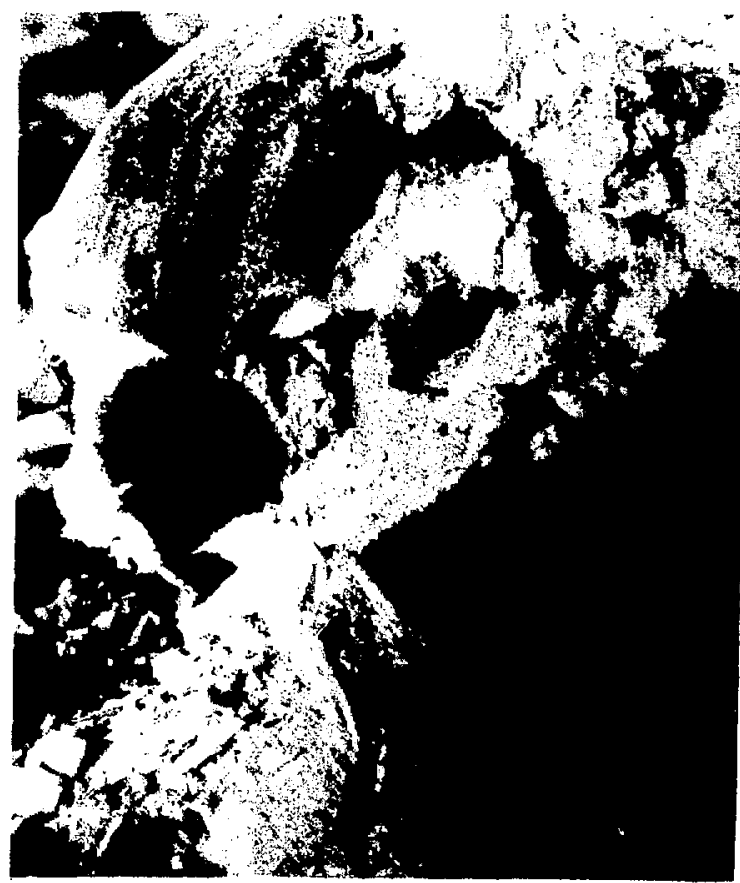

Fig. 15.

Close-up view of oxidation products. The needles are $\mathrm{MoO}_{3}$ formed from the molybdenum component in the fuel simulant. 


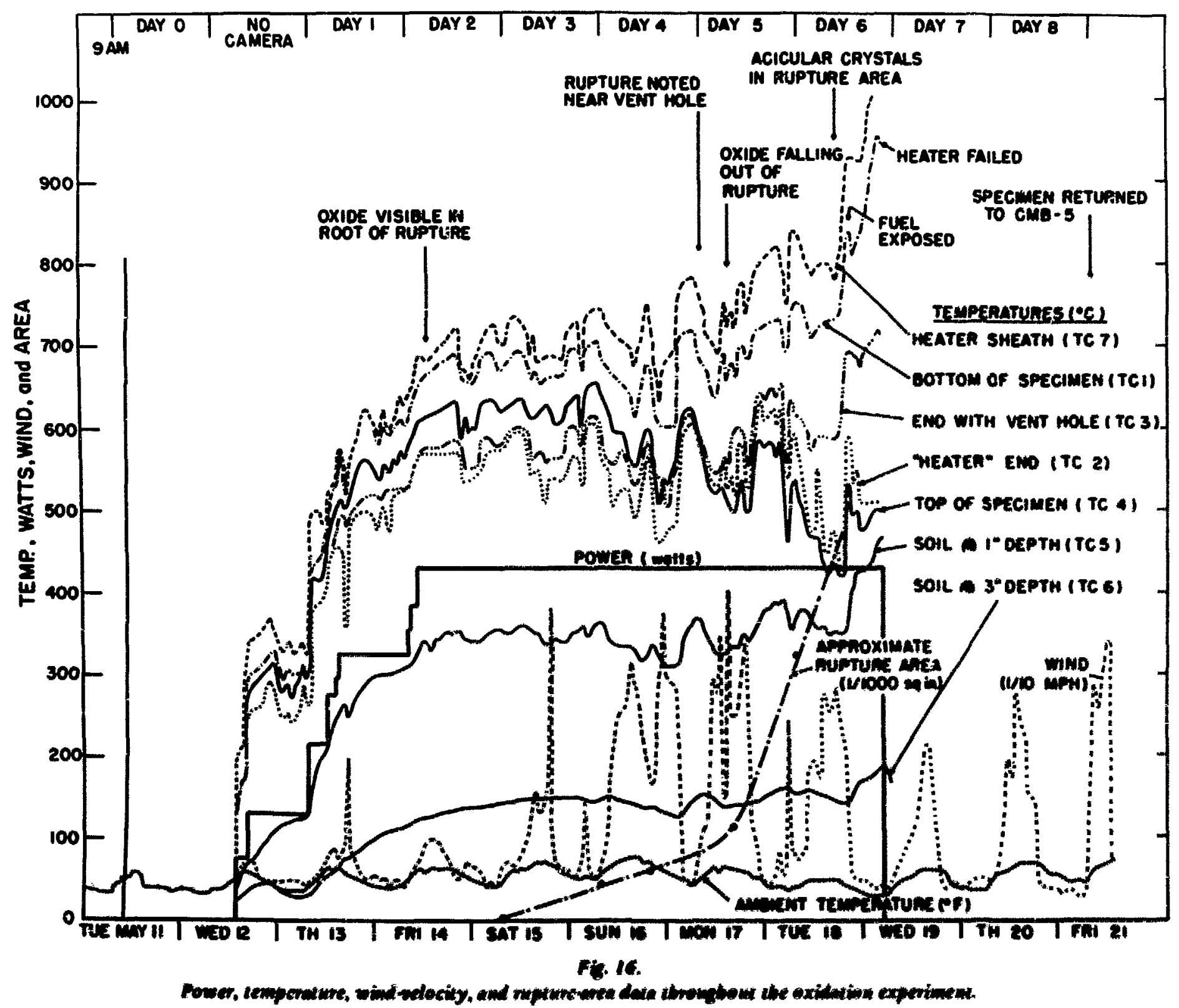




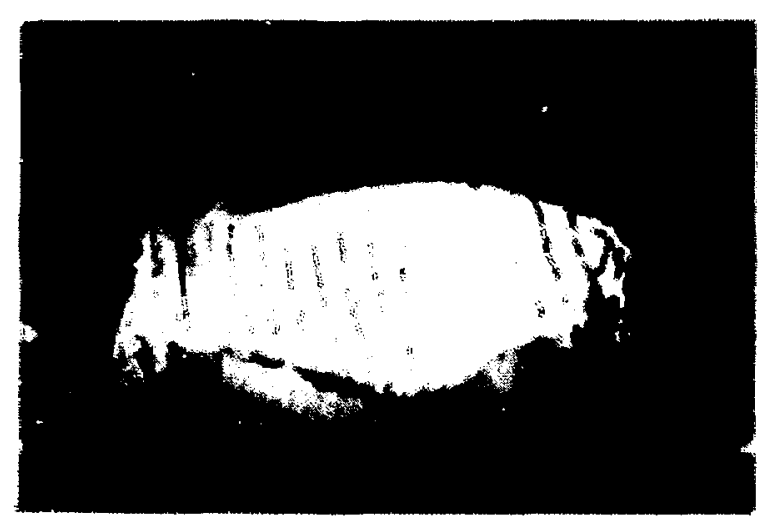

Prot.

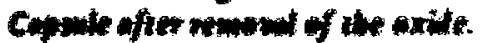

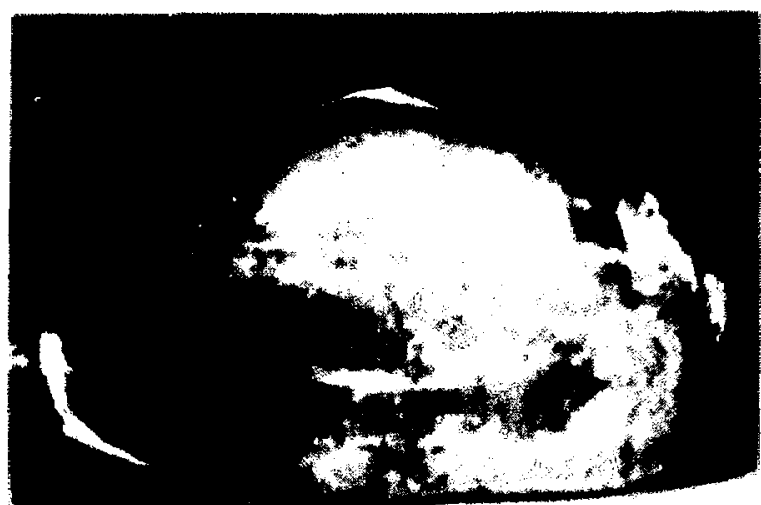

Fis. 19

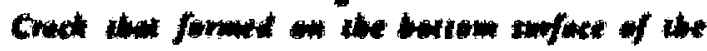

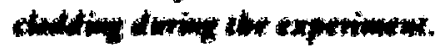

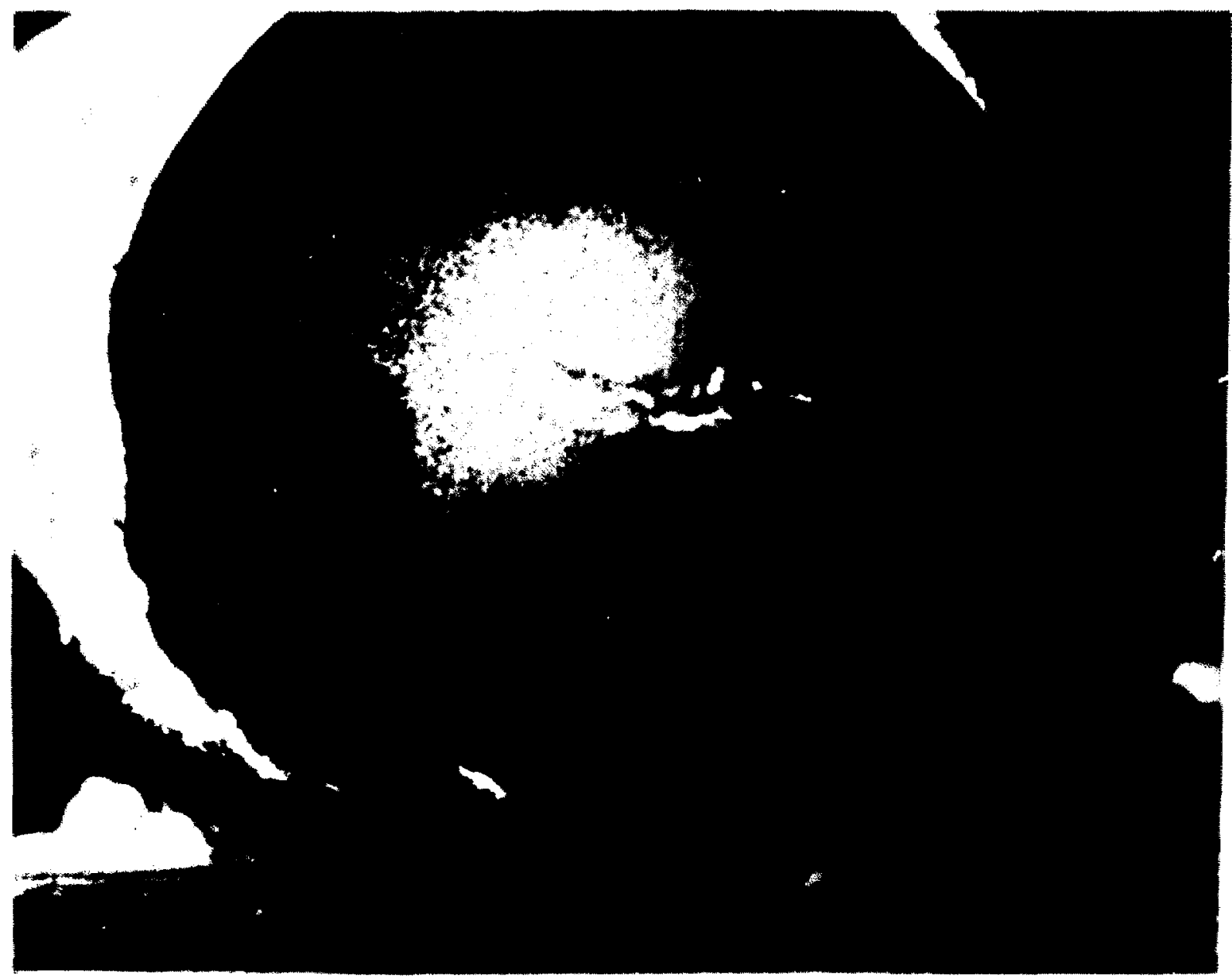

Fr. 19.

Vented end of apsule of ter bouter foiture. 


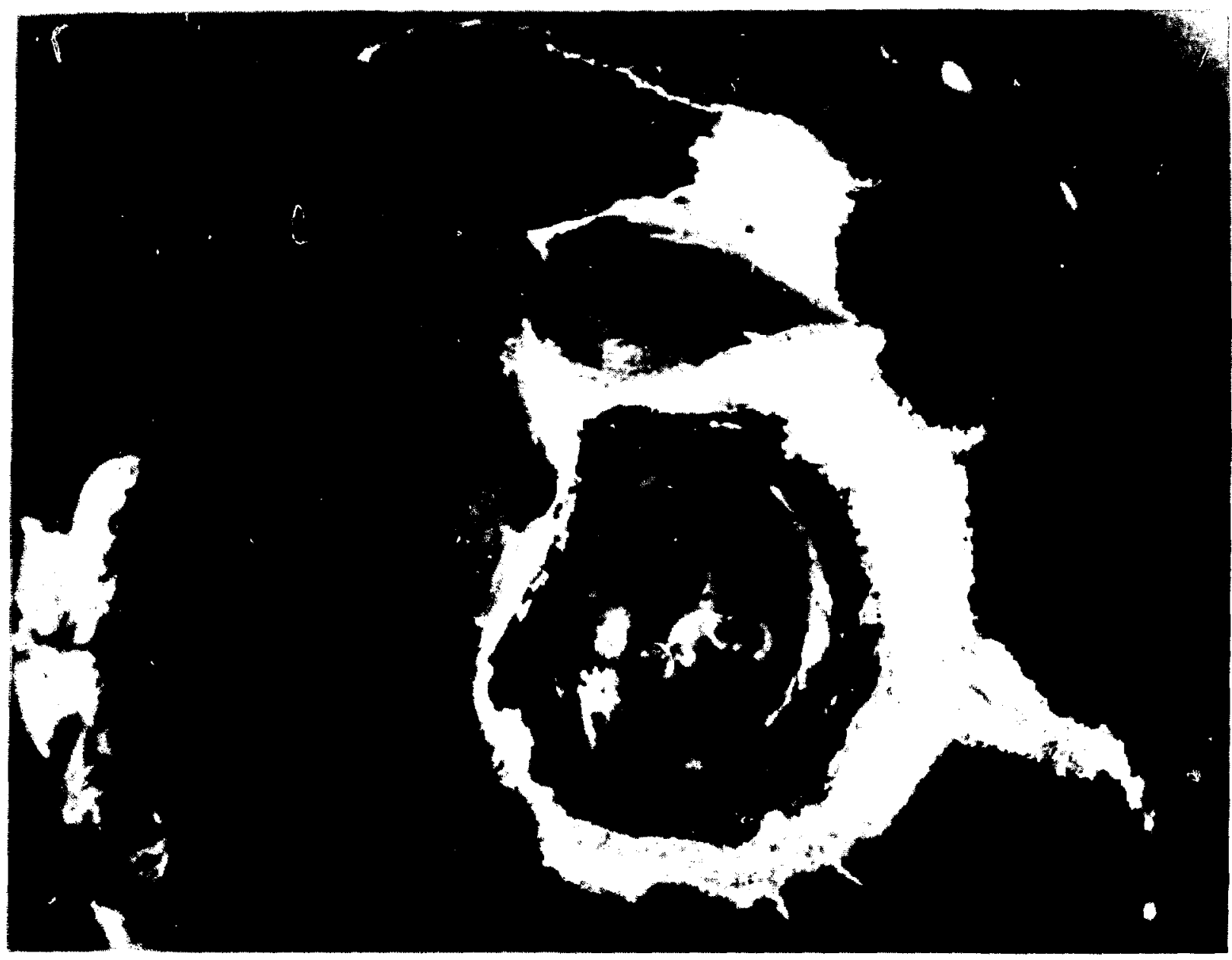

Fit. 20.

Hater cond of capsole after beater foilure.

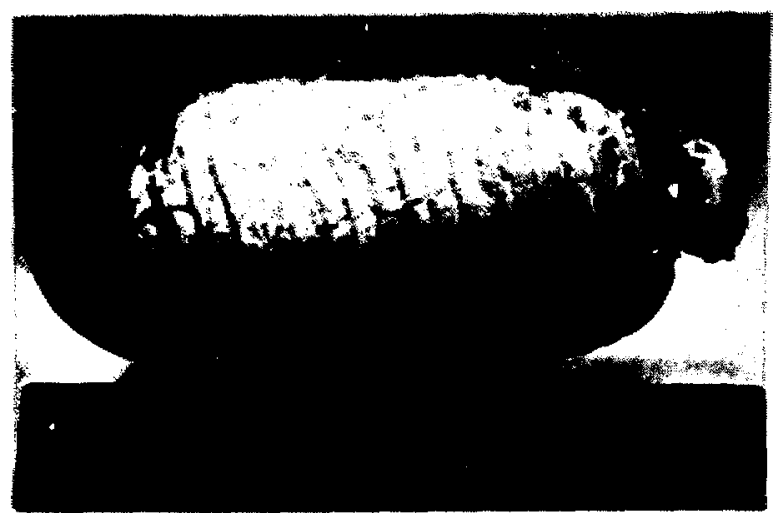

Fic. 21.

Copsule witb dulling remoned to show the region in wbich oxilation of the strengtb member and biner was complete.

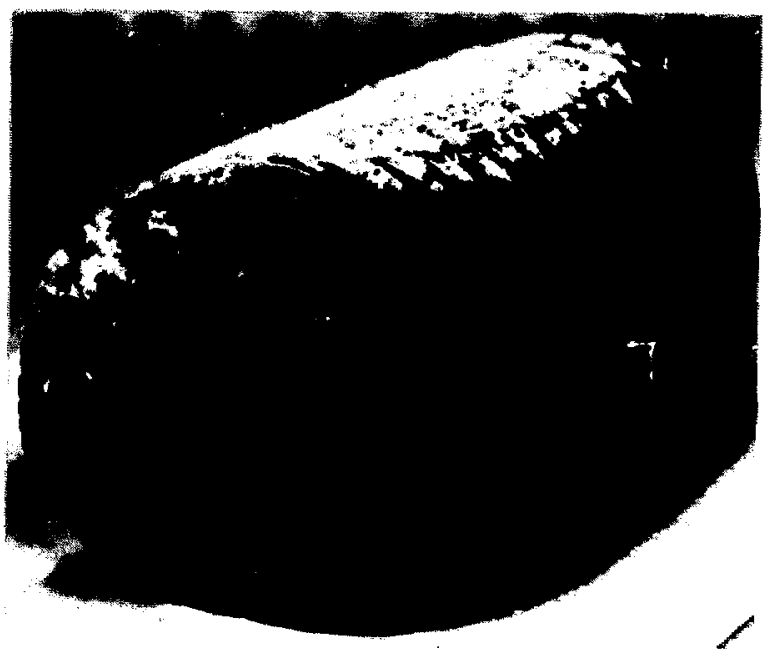

Fig. 22.

Fuel simuiant after removal from the capsule, sbowing its general wnoxidited condition. 